\title{
Educação, inclusão e direitos humanos: como esse estuário desaguou na escola?'
}

\author{
Erika Souza Leme* \\ Valdelúcia Alves da Costa**
}

\section{Resumo}

Neste trabalho a Declaração Universal dos Direitos Humanos (UNESCO, 1948) é analisada como pressuposto fundamental, tanto por ampliar as conquistas sociais quanto por possibilitar o exercício da democracia social e da liberdade do indivíduo, mesmo no contexto dos limites sociais e das condiçôes objetivas materiais ainda vigentes no estágio civilizatório contemporâneo. Em consonância com esses princípios, este trabalho analisa a inclusão em educação na perspectiva crítica, demandando a participação coletiva com vistas à superação das barreiras que obstam a afirmação do direito à educação. Assim, o direito propalado impóe demandas desafiadoras à sociedade, uma vez que as leis per si não democratizam a escola e, sim, as experiências pedagógicas inclusivas de seus profissionais, familiares e comunidade. Esse desafio consubstancia esta pesquisa, realizada em um colégio público de ensino médio na cidade do Rio de Janeiro, que decorreu ao longo de um ano letivo, período no qual foi possibilitado acesso aos documentos oficiais, bem como aos professores e gestores. Sustentado pelo referencial da teoria crítica, com ênfase no pensamento de Adorno, e pelo referencial conceitual-analítico do Index para Inclusão, que implica na articulação entre as dimensões de construção de culturas, desenvolvimento de políticas e orquestração de práticas (BOOTH; AINSCOW, 2002), é desenvolvida a discussão tendo por base as concepçóes dos professores quanto ao direito à educação, como também a reflexão sobre as questôes que se constituem como demandas e desafios no estabelecimento efetivo de experiências inclusivas no cotidiano das escolas públicas.

Palavras-chave: Educação e inclusão; Direitos humanos; Formação de professores.

* Professora doutora da Universidade Federal Fluminense, Niterói, Rio de Janeiro, Brasil.

** Doutoranda em Educaçáo pela Universidade Federal Fluminense, Niterói, Rio de Janeiro, Brasil. 


\section{Education, Inclusion and Human Rights: As this Estuary flowed at school?}

\section{Abstract}

In this work, the Universal Declaration of Human Rights (UNESCO, 1948) is analyzed as a fundamental theory, not only for extending the social conquest but for becoming possible the exercise of social democracy and individual liberty, even in a context of social limits and objective material conditions, still in course in the contemporary civilization level. In consonance with these principles, this work analyses the education inclusions in a critic perspective, demanding social participation, in sight of breaking barriers that become obstacles against to the affirmation about education rights. So, the widespread right calls for challenging demands to society, once the laws themselves do not democratize the school, but the inclusive pedagogic experience of its professional, family and community. This challenge consubstantiates this research that took place in a public high school in Rio de Janeiro city, along the year, when it was possible to get access to official documents and to change ideas with the teachers and the head teacher as well. Sustained by referential of critical theory, emphasized by Adorno's thoughts and by analytical-concept index toward inclusion, that implicates the articulations among the culture, politic development and orchestration of practice construction ( BOOTH; AINSCOW, 2002), is developed a discussion based on professor's concept about the education right and also a reflection about questions that constitute themselves as demand challenges in a effective establishment of inclusive experiences, in a daily public school.

Keywords: Education and inclusion; Human rights; Professors' formation.

A inserção da educação no contexto dos direitos humanos traz à tona sua relevância por se tratar do esclarecimento necessário ao exercício de outros direitos humanos, tal dimensão impõe à educação escolar o viés de "fundante da cidadania, e tal princípio é indispensável para políticas que visem à participação de todos nos espaços sociais e políticos.” (CURY, 2002, p. 246)

No âmbito nacional, a Constituição Federal da República Brasileira vigente (BRASIL, 1988) adota a Declaração Universal dos Direitos Humanos (UNESCO, 1948), como base e, com isso, passa a garantir a educaçáo e acesso à escola a todos os cidadãos sem nenhuma distinção. Os artigos $5^{\circ}$ e $205^{\circ}$ asseguram, respectivamente, "o direito de todos à educação" e a "igualdade de condiçôes de acesso e permanência na escola”.

Desse breve retrato do ordenamento jurídico brasileiro, em relação ao direito universal à educação, queremos destacar suas influências e seus desdobramentos. Essa tarefa envolve a análise das previsôes legais até a execução das mesmas, dueto que nem sempre está em consonância, pois as políticas colocam problemas que precisam ser resolvidos no contexto de seus sujeitos. 
Tendo em vista que o processo de inclusão se materializa na escola, no que tange à educação, defendemos a articulação entre políticas e práticas, uma vez que a afirmação das políticas públicas de inclusão em educação está atrelada às experiências cotidianas dos alunos nas escolas. Portanto, é no cotidiano que se define a participação e a gama total de experiências de aprendizagem vividas pelos alunos, as quais podem contribuir à formação humana emancipadora e inclusiva.

\section{Declaração Universal dos Direitos Humanos (UNESCO, $1948)^{2}$}

A Declaração Universal dos Direitos Humanos (UNESCO, 1948) retrata, de certo modo, a repulsa da sociedade no tocante às barbáries históricas cometidas contra os povos. Portanto, antes de ser inscrita numa constituição ou num texto jurídico, anuncia-se sob a forma de movimentos sociais, de tensóes históricas que propalam novos modos de sentir e pensar.

A despeito de possuir enraizamento social decorrente do combate de ideias em face das pressóes dos poderes estabelecidos e dos modos de governo, a referida Declaração não extrapola os limites e as marcas da sociedade ocidental. Sua elaboração conta com a interpretação do grupo hegemônico. Em suma, é a celebração do múltiplo para a sedimentação do único, isso é, dissimula as relaçóes desiguais de poder, propalando a relação de igualdade entre os povos e os indivíduos.

Dentre os artigos que a compóem, destacamos dois, devido ao interesse deste estudo, por tratarem da igualdade e da educação. São eles, respectivamente:

Artigo I - Todos os homens nascem livres e iguais em dignidade e direitos. São dotados de razão e consciência e devem agir em relação uns aos outros com espírito de fraternidade.

Artigo XXVI - I) Todo o homem tem direito à instruçáa. A instrução será gratuita, pelo menos nos graus elementares e fundamentais. A instrução elementar será obrigatória [...].

A Declaração Universal dos Direitos Humanos não discrimina os sujeitos dos direitos nela proclamados, e sim os situa em termos de igualdade, conforme o artigo primeiro. A questấo é que o princípio universal da igualdade propalado, muitas vezes, nâo se sustenta em situaçóes específicas, nas quais os sujeitos estáo contextualizados, como argumenta Flores (apud SARMENTO, et al, 2010, p. 113-114):

\footnotetext{
La conquista de la igualdad de derechos no parece haberse apoyado ni parece haber impulsionado el reconocimiento de, y el respeto por, las diferencias, ni, por supuesto, la remoción de las desigualdades sociales, económicas y culturales. El afán homogeneizador ha primado sobre el reconocimiento de las desigualdades, así como, de la pluralidad y la diversidad. (FLORES apud SARMENTO, et al, 2010, p. 113-114).
}

De que nos serve a igualdade propalada diante das diferenças econômicas, políticas e sociais na qual a humanidade se encontra? Há ambiguidade na Declaração Universal dos Direitos Humanos? Ela cria espaço político para diferentes lutas pela 
igualdade de oportunidades, mas também delimita as reivindicações no quadro específico dos direitos humanos, do liberalismo dos direitos civis e do culto à lei como instrumento de vontade geral no constitucionalismo democrático.

Entretanto, isso não diminui a importância da Declaração Universal dos Direitos Humanos, tendo em vista que a mesma representa uma conquista em termos de políticas sociais, posto que ressaltou o valor da solidariedade (fraternidade) e modificou a compreensão do direito à igualdade no sentido material, contra a desigualdade social. Cumpre destacar que as conquistas sociais passaram a exigir uma relação complexa entre Estado e cidadáo, na qual os direitos alcançados por este representavam em contrapartida deveres prestacionais do Estado. (BOBBIO, 2004)

Ao declarar que "todos os homens nascem livres e iguais em dignidade e direitos" (art. I), insere a dignidade no contexto da igualdade. Assim, a relação de igualdade é reconhecida como dever do Estado, conforme nos explica Tavares (2003, p. 158), "[...] em relação aos direitos sociais, o da dignidade humana resulta da obrigação de o Estado garantir um mínimo de recursos materiais suficientes para que, a partir daí, a pessoa possa exercer sua própria autonomia”. Desse modo, criam-se as condiçóes para a isonomia de oportunidades, além de reconhecer a solidariedade como valor universal.

Eis o grande avanço dos Direitos Humanos (1948), trazer à cena a responsabilidade do Estado no que tange à desigualdade social. Além disso, pode ser considerada como marco de luta pela paz entre os povos, no dizer de Bobbio (2004, p. 01) "Haverá paz estável, uma paz que não tenha a guerra como alternativa, somente quando náo existirem cidadáos deste ou daquele Estado, mas sim do mundo". Cumpre destacar que a Declaração dos Universal dos Direitos Humanos representa o esforço pela paz, num momento em que o mundo sofria os terrores de uma guerra.

Quanto à necessidade da paz, como possibilidade de se contrapor à violência, é importante afirmar que a inclusão em educação tem um papel político central em seu combate, seja em sua forma abertamente visível, seja em suas formas mais sutis, ao propor uma pedagogia colaborativa, que não estimule a competitividade entre alunos e professores, como alternativa democrática para propiciar aprendizagem, materializando uma forma de resistência contra toda e qualquer prática violadora dos direitos à vida, à participação na sociedade e à dignidade dos indivíduos.

\section{A Constituição Cidadã}

No âmbito nacional, a Declaração Universal dos Direitos Humanos foi inserida na Constituição da República Federativa do Brasil - CRFB/1988 (BRASIL, 1988). Essa, que ficou conhecida como a 'Constituiçẫo Cidadã', veio alicerçada em Princípios Fundamentais como da Dignidade da Pessoa Humana, da Igualdade, da Função Social da Propriedade, dentre outros e, naturalmente, ratificou as Convençôes e Tratados Internacionais de Direitos Humanos.

Ainda assim, sua elaboração reflete o embate que se verificava entre as duas correntes ideológicas que compunham a Assembleia Nacional Constituinte, em que 
de um lado se encontravam os defensores das posições liberais e compunham o chamado "Centrão" e, do outro, aqueles que propugnavam uma Constituição com perfil social.

O resultado desse confronto foi o advento de uma Constituição que incorporou os ideais de ambas as correntes, como verificado desde seu preâmbulo, em que se anuncia a liberdade, o bem-estar e a igualdade como alguns dos valores supremos. Assim, foi inserido na Constituição Federal - CF/1988, um extenso rol de direitos dos cidadãos e que, em contrapartida, representam deveres, prestações por parte do Estado cujos objetivos são, dentre outros, promover a dignidade e a igualdade de oportunidades aos seus cidadãos.

Esses direitos previstos na Carta Magna Brasileira atual estão alicerçados em Princípios Fundamentais e, dentre eles, merece destaque o da Igualdade, que tal como posto na Constituição, representa uma igualdade de possibilidades, cujo cerne é a redução da desigualdade. Assim, segundo Moraes (2006, p. 33):

A Constituição Federal de 1988 adotou o princípio da igualdade de direitos, prevendo a igualdade de aptidão, uma igualdade de possibilidades virtuais, ou seja, todos os cidadáos têm o direito de tratamento idêntico pela lei, em consonância com os critérios albergados pelo ordenamento jurídico. Dessa forma, [...] o tratamento desigual dos casos desiguais, na medida em que se igualam, é exigência tradicional do próprio conceito de justiça. (MORAES, 2006, p. 33).

Portanto, a igualdade incorporada à atual Constituição Brasileira não se trata daquele mero conceito formal de cunho liberal, surgido a partir do século XVIII e táo difundido com a Revolução Francesa, e que serviu de respaldo teórico à classe burguesa para extinguir os privilégios da nobreza e do clero de modo a, por consequência, acabar com o regime absolutista. Assim, essa igualdade, consagrada nas constituiçóes liberais oriundas das revoluçôes oitocentistas americana e francesa representava, tão somente, ter o mesmo tratamento perante à lei, não incumbindo ao Estado qualquer ação ao contrário; este deveria não interferir nas oportunidades de cada um, como se depreende em Tavares (2003).

Não representa, tampouco, o ideal defendido pelas teorias socialistas do século XIX, de que o Estado deveria tornar todos iguais, ou seja, acabar com as diferenças sociais, com as classes sociais, fazendo com que todos fossem iguais quanto às condiçôes econômicas e sociais. (Idem)

Assim sendo, o Princípio da Igualdade que consta, por exemplo, nos artigos $5^{\circ}$ e $205^{\circ} \mathrm{da} \mathrm{CF} / 1988$, tem como objetivo, se não acabar, ao menos reduzir as desigualdades econômicas e sociais e, desse modo, promover a justiça social. Em consonância com esse entendimento, Tavares (2003, p. 53) explica acerca da igualdade material:

A igualdade vinculada à dignidade da pessoa não compromete o Estado a distribuir bens para tornar todos iguais, mas exige que este assegure as condiçôes mínimas necessárias às pessoas contra uma existência degradante. A igualdade de oportunidades pressupóe, como valor, não a igualdade simétrica, mas a inexistência da desigualdade aviltante. (TAVARES, 2003, p. 53). 
Desse modo, para se assegurar uma igualdade de oportunidades àqueles que se encontram em flagrante desigualdade, é imprescindível a intervenção do Estado por meio de políticas sociais. Assim, incumbe ao Estado ser o agente promotor de açôes que possibilitem a inclusão de parcela da população e possam transformar a realidade social, econômica e cultural, de modo a se obter a igualdade material ou substancial.

Assim, pode-se resumir que a igualdade material é complementar à formal, posto não ser suficiente à lei declarar que todos sáo iguais, devendo, além disso, prover mecanismos para alcançá-la. Em relação à Educação, tanto o seu desenvolvimento quanto o acesso à escola são garantidos na $\mathrm{CF} / 1988$ a todos os cidadáos sem nenhuma distinçáo. Os artigos $5^{\circ}$ e $205^{\circ}$ asseguram, respectivamente, "O direito de todos à educação" e a "Igualdade de condiçôes de acesso e permanência na escola".

Portanto, para que todos tenham oportunidade de acesso, faz-se mister a igualdade de oportunidades, independentemente das condições individuais. É nesse sentido, entáo, que a Constituiçáo afirma ser o acesso e a permanência na escola baseados no princípio da igualdade.

Esse princípio é uma garantia de que não serão adotados critérios teóricos ou práticos que afastem ou impeçam o exercício de direitos protegidos e garantidos pela lei. Sua existência também implica respeito às diferenças individuais e a obrigatoriedade de serem oferecidos serviços que atendam às necessidades de todos.

Desse modo, ao lado do direito à igualdade, surge, também, como direito fundamental, o direito à diferença. $\mathrm{O}$ reconhecimento da diferença implica o reconhecimento da diversidade humana como um valor. Sendo assim, não podemos deixar de fazer a distinção entre as diferenças consideradas naturais (espécie humana) daquelas de origem social, econômica e cultural. Isso implica reconhecer novas formas de organização de mundo, para que aqueles indivíduos com uma história de vida diversa possam vir a participar na construção de novas e justas estruturas sociais e políticas, e com isso contemplar os diferentes povos.

Desse modo, a educação como direito e sua efetivação em práticas sociais se convertem em instrumento de redução das desigualdades e das discriminaçóes e possibilitam uma aproximação pacífica entre os povos de todo o mundo. Fundamento este que orienta a proposta de inclusão em educação, conforme Booth (apud SANTOS, 1999, p. 3):

Por "orientação inclusiva" entendemos os esforços empreendidos pela instituiçáo educacional (e seus membros) no sentido de se minimizar, ou eliminar, as barreiras que estudantes possam sofrer e que os impeçam de participar plenamente da vida acadêmica, por conta de suas diversidades oriundas de gênero, etnias, condições sociais, situaçôes familiares, religião, habilidades acadêmicas, etc.

No contexto atual, toda política em matéria de educação traz, em seu bojo, sinais de sua evolução; o que outrora preconizava o direito à educação, hoje, busca responder aos desafios da diversidade humana, tendo como base a garantia de acesso e participaçáo de todos os alunos à escola, assim como à sociedade. Para tanto, a 
Comissão Internacional sobre Educação para o século XXI lembra que as políticas educativas devem ser suficientemente diversificadas e concebidas de modo a não serem mais uma causa de exclusão social (UNESCO, 1996). Nesse sentido, cabe às escolas romper com a tradicional natureza elitista do sistema de ensino, que possibilita sucesso para alguns enquanto exclui muitos outros. Esses legados estáo basicamente arraigados em nossas escolas e na sociedade, por isso não podem ser simplesmente subtraídos pelos políticos ou facilmente transformados por aqueles que planejam as reformas educacionais.

Quanto a isso, Adorno (1996, p. 1), enfatiza que as:

Reformas pedagógicas isoladas, indispensáveis, não trazem contribuições substanciais. Poderiam até, em certas ocasióes, reforçar a crise, porque abrandam as necessárias exigências a serem feitas aos que devem ser educados e porque revelam uma inocente despreocupação frente ao poder que a realidade extrapedagógica exerce sobre eles. Igualmente, diante do ímpeto do que está acontecendo, permanecem insuficientes as reflexôes e investigaçóes isoladas sobre os fatores sociais que interferem positiva ou negativamente na formação cultural, as consideraçôes sobre sua atualidade e sobre os inúmeros aspectos de suas relaçóes com a sociedade, pois para elas a própria categoria formação já está definida a priori. (ADORNO, 1996, p. 1).

Portanto, há que se pensar na formação dos professores, uma vez que as reformas educacionais por si só não são suficientes por não alcançarem os objetivos que propóem, porque as mesmas precisam do protagonismo dos professores, e esses por sua vez, necessitam de formação emancipadora.

\section{No Cotidiano da Escola}

Compreender como os professores lidam com o processo de inclusão na escola é possibilitar uma discussão mais palpável acerca deu seu próprio cotidiano, tendo em vista a possibilidade de desvelar as influências com que esses processos constituem e são constituídos no interior do colégio. Para levantarmos as percepçôes e as práticas desenvolvidas e vivenciadas na escola pelos professores, a respeito dos processos de inclusão em educação, aplicamos um questionário misto.

Nesse trabalho damos destaque a duas questôes, uma referente à percepção e a outra acerca da prática, sendo elas:

"2.1) Escreva, no quadro abaixo, quatro palavras que vêm à sua cabeça quando o assunto é inclusáo em educaçáo. Marque um X ao lado das duas palavras que você considera mais importantes. Justifique suas escolhas".

"2.3) Eu sou inclusivo quando"

A questão 2.1 está alicerçada na técnica de evocação livre, que tem por fim verificar a frequência das palavras que vêm à tona quando interpelamos sobre a inclusão em educação. Fundamentados em Bardin (1977, p. 52), para quem essa técnica também é conhecida como teste por associação de palavras que "Permite, em psicologia 
clínica, ajudar a localizar as zonas de bloqueamento e de recalcamento de um indivíduo". Ou seja, com base nessa técnica conseguimos captar os estereótipos produzidos pela cultura e incorporados pelos indivíduos no seu processo de formação. Já a questão 2.3 representa nosso intuito em conhecer se há ou náo contradiçôes entre o pensar e o agir. Em seguida, submetemos os dados coletados à Análise de Conteúdo (BARDIN, 1977).

A análise de dados da questão 2.1 envolveu a aplicação do software EVOC , o qual nos forneceu a análise quantitativa da frequência de evocação. Vejamos os resultados obtidos na tabela 1 :

Tabela 1 - frequência de evocaçóes acerca da inclusão em educaçáo (total de professores participantes 30 . Sendo: $21(70 \%)$ feminino e $9(30 \%)$ masculino).

\begin{tabular}{l|l|l}
\hline $\begin{array}{l}\text { Palavras que expressam } \\
\text { valores inclusão em educação }\end{array}$ & $\begin{array}{l}\text { As mais evocadas dentre os } \\
30 \text { questionários e \% }\end{array}$ & $\begin{array}{l}\text { No vezes que a palavra } \\
\text { foi marcada como mais } \\
\text { importante em relação à } \\
\text { frequência e \% }\end{array}$ \\
\hline Participaçáo & $7(23 \%)$ & $2(29 \%)$ \\
\hline Respeito & $6(20 \%)$ & $4(67 \%)$ \\
\hline Oportunidade & $5(17 \%)$ & $3(60 \%)$ \\
\hline Igualdade & $5(17 \%)$ & $4(80 \%)$ \\
\hline
\end{tabular}

Fonte: LEME, Erika Souza. Inclusão em Educação: das políticas públicas às práticas do cotidiano escolar. Dissertação (Mestrado em Educação) - UFRJ, 2011, p. 165.

A tabela 1 permite verificar as crenças, concepçóes e valores dos professores acerca da inclusão em educação. Notamos que as 4 (quatro) palavras mais evocadas pelos participantes são reveladoras por trazerem em seu cerne a perspectiva de inclusão como direito de todos à educação, sendo esse o princípio fundamental da educação emancipadora e genuinamente inclusiva. É importante destacar que quando usamos o termo participaçáo, queremos dizer que:

A participação significa aprender junto com outros e colaborar com eles em experiências compartilhadas de aprendizagem. Isto requer um engajamento ativo com a aprendizagem e ter algo a dizer sobre como a educação é experienciada. Mais profundamente, trata-se de ser reconhecido, aceito e valorizado pelo que se é. (BOOTH \& AINSCOW, 2002, p. 7).

Por outro lado, as palavras respeito, oportunidade e igualdade representam os valores propalados na Declaraçáo Universal dos Direitos Humanos (1948). Para além desta declaração, o precedente do princípio da igualdade foi conclamado por Rui Barbosa, em 1920, em seu discurso, Oração aos Moços, quando paraninfo da Faculdade de Direito de São Paulo:

A regra da igualdade não consiste senão em aquinhoar desigualmente aos desiguais, na medida em que se desigualam. Nesta desigualdade social, proporcionada à desigualdade natural, é que se acha a verdadeira lei da igualdade. $\mathrm{O}$ mais são desvarios da inveja, 
do orgulho, ou da loucura. Tratar com desigualdade a iguais, ou a desiguais com igualdade, seria desigualdade flagrante, e não igualdade real. (BARBOSA, 1999, p.19).

Tal desafio persiste na escola que sempre foi o locus da diferença mas, na atualidade, com a obrigatoriedade do ensino básico, possibilitou a ampliação com a presença de muitos outros totalmente diferentes entre si. Entretanto, tal diversidade foi descaracterizada pela escola em razão da predominância de políticas e práticas de padronização dos anseios e das experiências pedagógicas, por não saber lidar com a diversidade. Em oposição a essa tendência, os professores do colégio estudado demonstraram, no questionário, afinidades com os valores inclusivos, logo, especulamos a possibilidade desses membros os materializarem em suas práticas no cotidiano da escola e, com isso, estabelecerem uma relação inclusiva com o desconhecido. Será que esses valores foram incorporados em suas práticas?

Para aprofundarmos nossa análise sobre as palavras mais evocadas e marcadas como mais importantes (dados da última coluna da tabela 1), apresentamos as justificativas apresentadas pelos participantes:

R21. A participação tem um papel importante na inclusão em educação;

R24. Participaçáo nas atividades e com seus colegas de turma;

$\mathrm{R} 10$. O respeito é o dever de todo trabalho;

R22. Respeitando o próximo, de modo geral, você supera as dificuldades;

R4. Incluir não significa, em educação, pelo menos, dar as mesmas metodologias, mas adequar o que se ensina a quem vai receber a informação;

R13. Porque todos merecem ter as mesmas oportunidades de avaliaçấo e aprendizagem;

R19. Acredito que o termo inclusão esteja diretamente associado à igualdade; (grifos nossos).

Por esses destaques percebemos a contemplação da existência humana em suas múltiplas possibilidades. Essa constatação nos leva a crer que esses professores reconhecem as diferenças e acreditam que as mesmas devam ser valorizadas (trabalhadas) no cotidiano da escola, resta saber se suas práticas condizem com seus ideais.

O tratamento dado aos dados da questão 2.3 está alicerçado nas três dimensóes de estudo: culturas, políticas e práticas de inclusão em educação (BOOTH \& AINSCOW, 2002). Ressaltamos que adotamos como caráter pedagógico uma 'lente de aumento' sobre o referencial conceitual-analítico, no intuito de captar a dimensáo predominante em relação às outras, mas não perdendo de vista a correlação direta entre as três dimensôes. Desse modo, iluminamos, ao menos em parte, as exigências e os desafios que se impóem ao cotidiano escolar. Lembramos que nem sempre as escolhas foram justificadas. Isso explica o número (menor) de justificativas expostas abaixo: 
Em relação à dimensão de práticas, buscamos identificar de que modo os professores promovem a inclusão no seu cotidiano:

\section{Questáo 2.3: Sou inclusivo quando:}

R. 7 Trato meus semelhantes (alunos, professores, funcionários, dentre outros) de forma humana!!!

R. 25 Reconheço que toda pessoa pode aprender.

A dimensáo de culturas nos permite identificar de que modo as crenças, os valores, as concepçóes e a compreensão do mundo no qual está inserido, representam limites ou possibilidades acerca da inclusão em educação:

\section{Questão 2.3: Sou inclusivo quando:}

R. 4 Respeito a origem de meu aluno e tento, de formas variadas, levá-lo ao aprendizado que não vai estigmatizá-lo.

R.12 Procuro aproveitar o que cada um tem de melhor, respeitando a individualidade e a heterogeneidade dos alunos.

Pela dimensáo de políticas pudemos compreender, com limitaçóes, o alcance das políticas internas do colégio em prol da inclusão de todos, a saber:

\section{Questão 2.3: Sou inclusivo quando:}

R. 6 Estou comprometida com o projeto político pedagógico da escola em que trabalho.

R.11 Aceito as regras de uma escola inclusiva.

R.21 Posso participar e ter as mesmas oportunidades na vida.

Esses dados revelam que as barreiras à aprendizagem e à participação dos estudantes são construídas e mantidas cotidianamente, por serem fruto de nossas concepçóes, crenças e valores (culturas), pelo modelo de gestão (política) e pelas reaçóes possíveis de cada professor (práticas). Portanto, a inclusão demanda compromisso de todos em todas as instâncias sociais. Daí, o imbricamento das dimensóes.

É fato que as respostas indicam as contradiçóes sociais. Uma vez que ora se apoiam nos ideais dos direitos humanos, ora trazem à tona o caráter subjetivo e, por isso, impreciso. Todavia, percebemos que os verbos utilizados sinalizam posturas críticas, com exceção do "aceito" e "posso participar", que sinalizam uma postura heterônoma, que significa, conforme Adorno (2010, p. 124), o professor "[...] tornar-se dependente de mandamentos, de normas que não são assumidas pela razão própria do indivíduo", em detrimento de uma postura ética e política que compele à luta pela participação nas instâncias sociais, sejam elas no colégio, em forma de planejamento, trabalho em equipe, na circulação de informaçôes, no currículo, na avaliação e, assim por diante. 
Se a educação inclusiva, de caráter democrático, almeja uma educação pacífica, crítica e emancipadora, então, que ela se volte ao diálogo por vias da gestão democrática, que os projetos pessoais se estruturem na experiência com os demais indivíduos e que a diversidade se expresse na matriz igualitária de todos.

\section{Considerações finais}

Discutir as barreiras do processo de inclusão em educação in locus, com ênfase nos professores, uma vez que esses são fundamentais para que as mudanças se efetivem nas escolas, eis a grande questáo do nosso trabalho.

De acordo com nossos referenciais, a ação do professor necessita estar em consonância com as questóes políticas, nấo como meros aplicadores sem discernimento, mas como cidadáos conscientes de seus direitos e deveres.

Ao longo do nosso trabalho, pudemos perceber certo afastamento desses atores das discussões políticas. Lembramos entender que a política abarca todo tipo de orientação, tais como documentos, atas, grades curriculares, projetos, projetos político-pedagógicos, circulares, portarias, regras disciplinares e quaisquer acordos sistematizados em documentos que os explicitem (SANTOS, 2010).

Esse afastamento, de certa forma, retroalimenta as exclusôes, a despeito dos avanços políticos. Nesse sentido, Horkheimer e Adorno (1985, p. 147), problematizam que "A humanidade não é autônoma e na qual os direitos humanos ainda não tenham sido realizados [em uma] medida mais concreta e decisiva do que a atual". Isso produz uma lacuna entre o direito afirmado e o direito usufruído, ou seja, os direitos humanos no discurso estão no centro, enquanto que na prática ainda são periféricos.

Nesse sentido, vale lembrar a questão levantada por Bobbio (2004) acerca dos direitos humanos, para quem a dimensão agora é outra, não mais a de justificá-los, mas a de protegê-los. Essa argumentação reforça nossa convicção a respeito da política, que não deve ser pensada apenas por quem a elabora e, sim, por quem a vivencia. O problema é que esta instância foi alijada das instituiçốes de ensino e da formação humana.

Diante dessa complexidade, partimos para o reconhecimento do processo de conscientização conforme Costa (2005, p. 130), que o considera "Sempre inacabado e contraditório, referindo-se a uma aproximação crítica das instâncias sociais, envolvendo desde as formas de consciência mais primitiva, até a mais crítica e problematizadora e, consequentemente, transformadora".

Em outras palavras, o processo de conscientização pressupóe uma postura curiosa e problematizadora diante do conhecimento e do mundo, que nos possibilite perceber o imperceptível, ouvir o indizível e, quiçá, entender melhor as intençôes que movem as açôes. Adorno (2010, p. 67-68) afirma que "O indivíduo só se emancipa quando se liberta do imediatismo de relaçóes que de maneira alguma são naturais [...]". Nesse sentido, "Emancipação significa o mesmo que conscientização, racionalidade" (Idem, p. 143). 
Isso implica em promover o conhecimento das questôes materiais e objetivas, isso é, sociais, políticas e econômicas que geram os processos de exclusão na sociedade contemporânea. A falta de consciência aprofunda a lacuna que existe entre a organização social vigente e a ação transformadora do indivíduo na sociedade em que vive.

\section{Referências}

ADORNO, T. W. Educaçáo e Emancipaçáo. São Paulo: Paz e Terra, 2010.

Teoria da Semicultura. Educaçáo \& Sociedade, Campinas, ano XVII, n. 56, p. 388-411, dez. 1996.

BARBOSA, R. Oraçáo aos Moços. Edição popular anotada por Adriano da Gama Kury. 5ed. Casa Rui Barbosa, 1999.

BARDIN, L. Análise de conteúdo. Lisboa: Ediçôes 70, 1977.

BOBBIO, N. A era dos direitos: tradução de Carlos Nelson Coutinho - Rio de Janeiro: Campus, 2004.

BOOTH, T.; AINSCOW, M. Index Para a Inclusão. Desenvolvendo a aprendizagem e a participação na escola. Traduzido por: Mônica Pereira dos Santos. Produzido pelo LaPEADE, 2002.

BRASIL, Constituiçáo da República Federativa do Brasil. Brasília, DF: Senado Federal, 1988.

COSTA, V. A. Formaçáo e teoria Crítica da escola de Frankfurt: trabalho, educação, indivíduo com deficiência. Niterói: EdUFF, 2005.

CURY, C. R. J. Direito à Educaçáo: Direito à Igualdade, Direito à Diferença. In Cadernos de Pesquisa, no 116, p. 245-262, julho/2002.

HORKHEIMER, M.; ADORNO, T. W. Dialética do esclarecimento: fragmentos filosóficos. Rio de Janeiro: Zahar, 1985.

MORAES, A. Direito Constitucional. 19 ed. São Paulo: Atlas, 2006.

SANTOS, M. P. Culturas, Políticas e Práticas de Formaçáo Docente para a Diversidade: Um desafio premente, mas nada atual. Trabalho escrito para apresentação de Simpósio no XV ENDIPE - Encontro Nacional de Didática e Prática de Ensino: Convergências e tensôes no campo da formação e do trabalho docente - políticas e práticas educacionais. 20 a 23 de abril de 2010.

SARMENTO, D.; IKAWA, D.; PIOVESAN, F. Igualdade, Diferença e Direitos Humanos. Rio de janeiro: Lumen Juris, 2010.

TAVARES, M. L. Previdência e Assistência Social Legitimação e Fundamentaçáo Constitucional Brasileira. Rio de Janeiro: Lúmen Júris, 2003.

UNESCO. Declaraçáo Universal dos Direitos Humanos, 1948. Disponível em: <http://www.dhnet.org.br/ direitos/deconu/textos/integra.htm>. Acesso em: 10 jan. 2016.

UNESCO, DELORS, Jacques et al. Educaçáo um tesouro a descobrir: relatório para a UNESCO da comissão internacional sobre educação para o século XXI. São Paulo: Cortez; Brasília, DF, 1996.

\section{Notas}

${ }^{1}$ Artigo resultante de trabalho apresentado no IV Congresso Argentino Latinoamericano de Direitos Humanos: "Diálogos Pluriculturais para a Equidade", em Rosário, Argentina, Maio, 2013. Refere-se a um recorte da Dissertação de Mestrado em Educação, intitulada 'Inclusão em Educação: Das Políticas Públicas às práticas do Cotidiano Escolar', defendida no Programa de Pós-Graduação em Educação, Universidade Federal do Rio de Janeiro, 2011.

${ }^{2}$ Em 10 de dezembro de 1948, a Assembleia Geral reunida em Paris, aprovou a Declaraçăo Universal dos Direitos do Homem com 48 votos a favor e oito abstençóes (Ucrânia, Polônia, Iugoslávia, URSS, Arábia Saudita, Bielo-Rússia, Uniāo Sul-Africana e Tcheco-Eslováquia). Na votaçáo em separado dos artigos da referida Declaraçáo, 25 deles foram aprovados unanimemente. Os países que se abstiveram, o fizeram pelas seguintes razóes: o Bloco Soviético reivindicava que se desse maior importância aos direitos econômicos e sociais; a Arábia Saudita afirmou que o pensamento mulçumano não influenciara a Declaraçăo; A União Sul-Africana porque há a interdição de discriminação racial. A Arábia Saudita na Declaraçăo Universal se opôs ao art. XVIII, porque no Chária abandonar o islamismo é digno de pena de morte. Pode-se acrescentar ainda que para a URSS os direitos humanos tinham origem no Estado e não na dignidade humana. Além desses, a maioria dos países africanos e asiáticos não participou na formulação da Declaração Universal 
de Direitos Humanos porque, como vítimas de colonização, eles não eram sócios das Naçôes Unidas. (MELLO, C. D. de A, Curso de direito internacional público. Rio de Janeiro: Renovar, 2004).

${ }^{3}$ PIOVESAN. F. Direitos Humanos e o Direito Constitucional Internacional. 3ed. São Paulo: Max Limonad,1997; destaca que a Declaraçáo dos Direitos Humanos (1948) associa o discurso liberal da cidadania com o discurso social.

${ }^{4}$ Software livre de registro, disponível em: <www.pucsp.br/pos/ped/rsee/evoc.htm>.

\section{Correspondência}

Erika Souza Leme - Universidade Federal Fluminense, Faculdade de Educação. Av. Visconde do Rio Branco, s/n. Gragoatá, CEP: 24000-021 - Niterói, Rio de Janeiro - Brasil.

E-mail: kikaleme@yahoo.com.br - valdelucia2001@uol.com.br

Recebido em 02 de abril de 2015

Aprovado em 06 de maio de 2016 